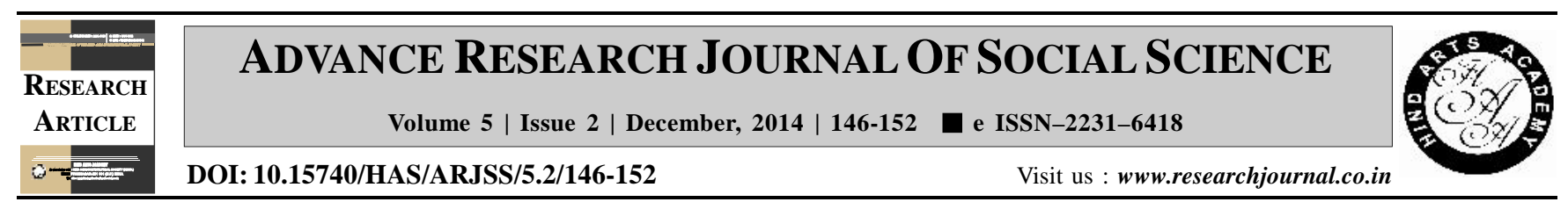

\title{
Item wise ranked information needs of tomato growers in Junagadh district of Gujarat
}

\author{
Girish Deshmukh* and Bhishman Sangada
}

Department of Agricultural Extension, Junagadh Agricultural University, JUNAGADH (GUJARAT) INDIA

(Email: 251girish@gmail.com)

\section{ARTICLE INFO :}

$\begin{array}{lll}\text { Received } & : & 10.10 .2014 \\ \text { Revised } & : & 28.10 .2014 \\ \text { Accepted } & : & 10.11 .2014\end{array}$

\section{KEY WORDS :}

Item wise ranked information

Need, Tomato growers

\section{HOW TO CITE THIS ARTICLE :}

Deshmukh, Girish and Sangada, Bhishman (2014). Item wise ranked information needs of tomato growers in Junagadh district of Gujarat, Adv. Res. J. Soc. Sci., 5 (2) : 146-152.

*Author for correspondence

\begin{abstract}
Tomato cultivation requires enough care right from nursery raising to post harvesting operations. Necessary package of practices must be followed for the better yield. It demands complete knowledge of methods and same must be followed by the tomato growers in right manner and at right time. The methodological procedure consisted of dependent and independent variables, setting and selection of the respondents, analysis of data and various statistical measures used to test the hypothesis. The information needs of tomato growers was availed on a three point continuum ranging from "Most Needed", "Needed" and "Not Needed". The information needs were worked out for each of the major areas considering the total score for information needs acquired by the respondents. The present investigation was carried out with 120 randomly selected samples of Junagadh district of Gujarat state in $n$ India. The data were collected with the help of structured schedule by personal interview method. The most important aspects of information needs nursery management, seeds or high yielding verities, fertilizer applications, pests and diseases management etc. were revealed in the study.
\end{abstract}

